\title{
Uso de memes em aulas de Português: um olhar voltado à inovação de práticas pedagógicas na área de Linguagens e Códigos
}

\section{Using memes in Portuguese classes: a look over the pedagogical innovating practices in the Languages and Codes area}

\begin{abstract}
Resumo: A pesquisa investiga as contribuições decorrentes da utilização de memes como ferramenta didático-pedagógica em aulas de Português. A análise traz subsídios à literatura vigente, no cerne das práticas colaborativas e inovadoras, ao abordar o uso deste gênero discursivo em sala de aula. Para efetivar a pesquisa qualitativa, os dados foram coletados por meio do oferecimento de uma oficina resultando nas observações, questionário e entrevista. Os participantes da pesquisa foram alunos do terceiro ano do Ensino Médio de uma escola localizada no Ceará, Brasil. Como resultados, o estudo apresenta novas alternativas para intervir em sala, tendo em vista as possibilidades de melhorar a colaboração entre os pares, o diálogo, a criatividade, a utilização de recursos digitais, a oratória e a visão otimizada relativa aos conteúdos de Português, além do entendimento do erro como parte integrante da aprendizagem. Logo, percebe-se que intervenções inovadoras em sala são substanciais na composição dos currículos escolares.
\end{abstract}

Palavras-chave: Inovação. Ensino de Português. Memes. Práticas educacionais.

Abstract: The research investigates the contributions arising from the use of memes as a didactic-pedagogical tool in Portuguese classes. The analysis brings subsidies to the current literature, at the core of collaborative and innovative practices, by addressing the use of this discursive genre in the classroom. To carry out the qualitative research, the data were collected through the offering of a workshop resulting in the observations, questionnaire and interview. Participants in the survey were third-year high school students from a school located in Ceará, Brazil. As results, the study presents new alternatives to intervene in the classroom, taking into account the possibilities of improving collaboration among peers, dialogue, creativity, use of digital resources, oratory and optimized view of the Portuguese content, in addition to understanding the error as an integral part of learning. Therefore, it is perceived that innovative interventions in the classroom are substantial in the composition of school curricula.

Keywords: Innovation. Teaching Portuguese. Memes. Educational practices.

\section{Introdução}

São notáveis, atualmente, os processos de inovação e ressignificação das práticas

\section{Luiz Fernando de Oliveira \\ Lopes \\ icenciando em Letras: Português e \\ Inglês pelo Instituto Federal de \\ Educação, Ciência e Tecnologia do \\ Ceará (IFCE), campus Baturité. Ceará, \\ iD orcid.org/0000-0002-9729-8899 \\ $\bowtie$ luizfernandooprof@gmail.com}

\section{Alisandra Cavalcante}

Doutora em Educação. Professora do Instituto Federal de Educação Ciência e Baturité. Ceará, Brasil.

(iD) orcid.org/0000-0002-7066-1504

$\triangle$ alisandra.cavalcante@ifce.edu.br

Recebido em 15/04/2020 Aceito em 22/05/2020 Publicado em 08/06/2020

doi $10.46551 /$ ees.e202006

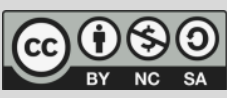




\section{Edurañãa,Escola\&Sociedace}

pedagógicas que contribuem, verdadeiramente, para a transformação dos espaços educacionais. Nessa tendência transformadora (FREIRE, 2013), mostrou-se interessante investigar a viabilidade da utilização do gênero discursivo meme, denominado nesta pesquisa como um Recurso Multimodal Digital: Meme (RMDM), facilitador do desenvolvimento de habilidades no campo da disciplina de Português.

O presente estudo investiga a proposta do emprego de memes como recurso impulsionador no ensino e na aprendizagem de Português, objetivando estruturar caminhos para a atualização de práticas pedagógicas, observando os desafios da educação na era digital, bem como estimar, por meio da pesquisa qualitativa, as contribuições constituídas por esse recurso.

Os espaços criados potencializaram a construção do conhecimento de maneira colaborativa e com recursos contemporâneos. Para tanto, foram propostos, na modalidade oficina, dois momentos para efetivação das atividades pretendidas, cada momento instituído por quatro horas. A oficina corroborou para a coleta e análise de dados quanto à aplicabilidade, potencialidade e aos eventuais desafios no uso desse aparato pedagógico. Os instrumentos de coleta consistiram nas observações das interações decorrentes dos dois momentos da proposta, bem como a realização de entrevistas abertas fundadas na definição de Haguette (1997); os participantes da pesquisa foram sete alunos cursando o terceiro ano do Ensino Médio.

Como diretrizes referenciais, foram eleitos os seguintes autores: Santaella (2014), que aborda a dinâmica cultural digital e a semiótica dos memes; Lendl e Pinheiro (2018), com as questões acerca da multimodalidade nesses recursos imagéticos e a relevância dessa discussão na contemporaneidade; Freire (1987; 2013), contemplando o papel emancipatório da educação e as relações escolares; Halliday (1985), com a Gramática Sistêmico-Funcional; e Dawkins (2007), responsável por formular, no sentido epistemológico, a palavra meme, dentre outros.

Os caminhos metodológicos dividiram-se em etapas predefinidas, visando favorecer o desenvolvimento estratégico da oficina, tanto para os participantes, como para uma coleta categórica de dados. Fez-se, assim, a ponderação entre o entendimento de pesquisa-ação de Lewin (1973), com o fundamento de favorecer a mudança social e de Elliott (2001), que abrange, em seus estudos, o teor formativo da pesquisa, principalmente a formação docente baseada em ações, cujo objetivo é sistematizar as análises, a fim de prover contribuições para o grupo investigado. 


\section{Eduraçãa,EsodarSociedtade}

Embora o uso de memes tenha se acentuado ultimamente, é preciso compreender os contextos que levaram ao surgimento dessa modalidade comunicacional. Um dos principais motivadores é o advento de mídias sociais mais dinâmicas e interativas, característica expressa no campo dos memes, que possuem amplo potencial comunicativo. Assim, infere-se que, do século XX até os dias atuais, os processos comunicativos vêm caminhando para evoluções mais dinâmicas e fluidas, incluindo o meme, que perpassa questões cotidianas até críticas político-sociais.

Nessa perspectiva, os elementos que compõem os memes são, essencialmente, as linguagens verbais, não verbais e os demais elementos semióticos do discurso, como vivências, cultura e as diferentes leituras que os integram. Pesquisas recentes indicam que a Educação deve ser perpassada por avanços proporcionados pelo uso da tecnologia. Rodrigues, Almeida e Valente (2017) versam sobre os parâmetros atuais da educação e da atuação docente que também é influenciada pelas conexões multimodais e hipermodais favorecidas pelas Tecnologias Digitais de Informação e Comunicação (TDIC).

Entretanto, registra-se, comumente, a carência tanto de equipamentos nas escolas, bem como um déficit na formação dos professores. O objetivo da pesquisa apresentada, portanto, foi investigar as contribuições advindas da utilização do RMDM como ferramenta didático-pedagógica em aulas de Português. A seguir, serão detalhados os caminhos metodológicos percorridos.

\section{Metodologia}

O estudo aqui retratado foi realizado em uma instituição federal no Estado do Ceará e teve como sujeitos de pesquisa sete alunos do terceiro ano do Ensino Médio da rede estadual de educação. Os participantes foram subdivididos em grupos, para agilizar a coleta das discussões com seus pares: Grupo 1 (G1) — Alunos 1 e 2 (A1 e A2); Grupo 2 (G2) Alunos 3, 4 e 5 (A3, A4 e A5); e Grupo 3 (G3) - Alunos 6 e 7 (A6 e A7).

Inicialmente, um planejamento preliminar alicerçou as escolhas pretendidas na investigação, de maneira a atender às expectativas; para isso, a oficina foi dividida em dois momentos, visando a favorecer a aprendizagem dos alunos e nossa ação na coleta dos dados.

As inscrições para a oficina ocorram por meio de um questionário on-line, no qual os alunos preencheram dados básicos como nome completo e a turma que faziam parte. A divulgação foi impulsionada com o auxílio no núcleo gestor da escola e com a fixação de 


\section{EdurañäsEscolakSociedade}

panfletos nos murais da escola com informações pertinentes da oficina, dividida em dois momentos compostos por quatro horas cada.

Antes da coleta de dados, em busca dos caminhos metodológicos definidos para a presente pesquisa, surgiram três etapas: (1) planejamento e delimitação do tema da oficina; (2) levantamento bibliográfico acerca das produções que permeiam a concepção e uso do gênero meme, em espaços educacionais; e (3) aplicação da oficina e análise dos dados.

Acerca do perfil dos sujeitos, os dados evidenciaram que todos os alunos nunca haviam sido reprovados. Ao serem questionados, cinco alunos afirmaram que sempre realizavam a leitura de livros, revistas ou jornais; todos os participantes tinham acesso à internet todos os dias; quatro alunos afirmaram navegar por mais de seis horas diariamente, enquanto os outros três praticantes navegavam de duas a quatro horas utilizando a internet; por fim, cinco alunos afirmaram ter a disciplina de Português como preferência, dentre as demais disponibilizadas na escola.

Ao longo da oficina e coleta de dados, foram observadas as etapas: (1) teoria e prática na produção de RMDM; (2) relacionar os RMDM com os conteúdos de Português, com a análise, na etapa 1 , da produção de reflexões nas interações por meio do diário de campo e questionários on-line e, na etapa 2, das reflexões surgidas por meio da composição dos enunciados realizados; e como instrumento de coleta foi utilizada, também, a entrevista aberta (HAGUETTE, 1997).

O objetivo foi o de buscar os dados na fonte, quando a oficina se concretizou, tendo um olhar sensível e aprofundado entre ações e situações ocorridas naquele momento. Estudos indicam que, ao observar o dia a dia, coletando informações das ações realizadas no contexto dos sujeitos, in loco, evidenciam-se questões de pesquisa importantes na descoberta e interpretação dos dados.

Pesquisar o uso do RMDM com alunos do Ensino Médio se adéqua à opção metodológica pesquisa-ação, pois a busca investigativa parte do próprio contexto de construção por parte dos alunos, que utilizam a realidade em diferentes situações práticas desenvolvidas no próprio objeto de estudo, sendo o professor detentor da ação e, ao mesmo tempo, observador-pesquisador (ELLIOTT, 2001). Os instrumentos de coleta foram desenvolvidos a partir das observações dos dois momentos com os alunos que, posteriormente, trouxeram subsídios para a formulação e direcionamento das entrevistas. Apoiado nesses dois recursos de coleta de dado pôde-se construir as reflexões presentes neste estudo. 
A seguir, o desenvolvimento e as discussões reflexivas sobre o objeto de estudo e os resultados após análises, serão dispostos.

\section{Novos espaços de aprendizagem: ressignificação das práticas pedagógicas}

A sociedade do século XXI estabelece relações estreitas com os recursos digitais; contexto expressamente notado, de modo igual, nos espaços educacionais. Nessa tendência, surgiu o objeto de pesquisa: investigar as contribuições advindas da utilização desses recursos em sala de aula. O recorte de pesquisa empenha-se em analisar o uso do RMDM como impulsionador do ensino e da aprendizagem de Português.

Esse recurso digital utilizado no cotidiano apresenta inúmeras possibilidades de emprego, visto que o processo de construção do gênero meme está ligado, fundamentalmente, às implicações pessoais e sociais, apresentando, assim, alternativas de relacionar-se com as diversas áreas do conhecimento.

Santaella (2014), ao apropriar-se de conceitos de dialogia e dialogismo de Bakhtin, incorpora-os às interações provenientes das mídias sociais, em especial o Facebook. O mesmo processo, em uma espécie de polifonia, ocorre com o RMDM, no qual “o dialogismo é comunicação interativa em que cada um se vê e se reconhece através do outro" e a "dialogia é o ato do diálogo, modo como os sujeitos se relacionam, movimento entre o eu e o outro" (SANTAELLA, 2014, p. 207).

Dessa maneira, as possibilidades de comunicação são envolvidas com recursos dinâmicos e pertencentes a um contexto, enquanto Bakhtin (1997) traçava sua teoria baseado em romances, a atemporalidade de seus conceitos permite-nos adaptá-los às formas de discursos atuais. Para Silva, Francelino e Melo (2017, p. 178), “o meme é considerado um gênero discursivo, pois possui uma ancoragem em um espaço de criação e de recepção por sujeitos reais". Como exposto, por tratar-se de um gênero discursivo, o meme torna-se um objeto de estudo retilíneo aos conteúdos de linguagens e códigos.

Para melhor compreender o seu emprego, portanto, faz-se necessário analisar as discussões que levaram ao surgimento do termo. Apontamos a definição de Dawkins (2007) como a mais integral, pois o autor faz um paralelo singular entre meme e gene, considerando as especificidades da função de cada um desses termos. Enquanto o gene está ligado diretamente à evolução humana, o meme, saindo do campo biológico, relaciona-se, intimamente, com as evoluções dos processos culturais, dentre eles, hábitos, práticas e 


\section{Edurañagescolar Sociedtare}

costumes.

Precisamos de um nome para o novo replicador, um nome que transmita a ideia de uma unidade de transmissão cultural, ou uma unidade de imitação. "Mimeme" provém de uma raiz grega adequada, mas eu procuro uma palavra mais curta que soe mais ou menos como "gene". [...] "meme" guarda relação com "memória", ou com a palavra francesa même. (DAWKINS, 2007, p. 330).

Embora, aparentemente, esse recurso não tenha relação com aulas de Português, a proposta surgiu na expectativa de potencializar os conhecimentos desenvolvidos cotidiana e socialmente pelos alunos, com vistas a associar um recurso contemporâneo e de vasta utilização social à sala de aula. Martino e Grohmann (2017, p. 96) denotam que

os memes encontram sua materialidade na forma de imagens, vídeos, frases, enunciados, discursos e mesmo práticas sociais presentes nos mais inesperados espaços, mas, em especial, podem ser encontradas no ambiente das mídias digitais, nos quais a proliferação de memes parece ser particularmente alta.

O alto grau de comunicabilidade dos memes reconfiguram as formas de diálogos entre os pares e remontam às habilidades a serem desenvolvidas em sala de aula. $\mathrm{O}$ hibridismo dos atuais processos de comunicação (SANTAELLA, 2014) faz com que o ensino de Língua Portuguesa se adéque às demandas do corrente contexto.

Outro fator relevante é a intertextualidade dos memes ao possibilitarem múltiplas aplicações em sala de aula, que percorrem a produção textual, interpretação de discurso, leitura multimodal, dentre outras. Nesse sentido, “o meme funciona como uma voz (que, em si, também é heterogênea) que perpassa uma infinidade de outras vozes (em forma de intertexto) no espaço da rede semântica da internet” (MEILI, 2014, p. 362).

Genericamente, os debates em torno da educação pretendem definir quais métodos são mais proveitosos para a aprendizagem. Em suma, existem duas linhas acerca de práticas de ensino: uma que defende a incorporação de tecnologias nos percursos metodológicos; e, outra, que segrega educação e tecnologias.

Mattar (2010, p. 53) aduz que, atualmente, “já não é possível separar assim tão claramente a tecnologias da educação, já não é possível pensar as duas coisas desvinculadas. Dependendo da tecnologia que você adote, os resultados do aprendizado, de que tanto gostam de falar os designers instrucionais, serão diferentes".

Nessa perspectiva, percebe-se que os processos de ensino caminham em consonância 
com os contextos e as evoluções tecnológicas, não de forma dependente, mas consorte. Essas implicações nos levam a repensar a prática docente a partir das correntes circunstâncias.

\title{
4 Percepções dos alunos acerca de novas práticas de ensino
}

Esta seção destina-se a externar e refletir as percepções dos alunos quanto aos momentos de construção dos memes e as implicações de inovar os métodos de ensino. Desse modo, fundamentamos nossa ação em espaços de construções reflexivas e possibilitadas pelo protagonismo discente, para tanto buscou-se

\begin{abstract}
assegurar um ambiente dentro do qual os alunos possam reconhecer e refletir sobre suas próprias ideias; aceitar que outras pessoas expressem pontos de vista diferentes dos seus, mas igualmente válidos e possam avaliar a utilidade dessas ideias em comparação com as teorias apresentadas pelo professor. De fato, desenvolver o respeito pelos outros e a capacidade de dialogar é um dos aspectos fundamentais do pensamento freireano (JÓFILI, 2002, p. 196).
\end{abstract}

Quando questionados, os alunos verificaram que a prática pedagógica a partir dos memes interfere na maneira como a aula se desenvolve. Os alunos A1, A3, A4 e A5 indicam que a metodologia usada proporcionou interação e colaboração, além de apresentar os conteúdos não apenas na teoria, como comumente ocorre na escola, mas também na prática. Os alunos A2, A5, A6 e A7 mencionaram que os memes trouxeram à aula diversidade e interação entre professores e alunos, o que modificou a maneira de ensinar e aprender.

Os alunos foram desafiados a relembrar aulas lúdicas, interativas ou "divertidas" antes vivenciadas. Seis mencionaram que já tinham participado de aulas como essas, “interessantes". Ao estabelecer relação entre essas aulas, mencionaram aulas de Educação Física (A1); jogos didáticos (A2 e A3); e lousa digital (A4). Práticas pedagógicas inovadoras envolvendo memes, portanto, mostram que os alunos desenvolvem hipóteses e indagações de maneira autônoma. Experimentar a flexibilização das atividades proporciona aos alunos a

capacidade de pensar, de indagar-se e de indagar, de duvidar, de experimentar hipóteses de ação, de programar e de não apenas seguir os programas a elas, mais do que propostos, impostos. As crianças precisam ter assegurado o direito de aprender a decidir, o que se faz decidindo. Se as liberdades não se constituem entregues a si mesmas, mas na assunção ética de necessários limites, a assunção ética desses limites não se faz sem riscos a serem corridos por elas e pela autoridade ou autoridades com que dialeticamente se relacionam. (FREIRE, 2000, p. 25). 


\section{Edurañãa,Escola\&Sociedace}

Sobre isso, o percurso formativo derivado de atividades com recursos que partem do contexto do aluno move-se para desenvolver habilidades de reflexão, participação e autonomia. Os alunos indicaram ser inovadora a aula utilizando memes e que "existem várias formas de estudar não só olhando um professor escrevendo" (A1); e que a aprendizagem vai além do tradicional e da leitura apenas de conteúdo. Aprender com os memes "estimula a criatividade pois estimula o processo de ler imagens" (A2; A5); "além de ser uma aula mais didática, o que é essencial para a melhoria da aprendizagem" (A4).

O desafio nas salas de aula está relacionado à motivação dos alunos, ou melhor, à falta dela. Destaca-se, nos espaços educacionais, a segmentação entre o que se aprende em sala e a realidade dos nativos digitais, dado que esses estão em constante interação com espaços virtuais dinâmicos, ativos e estratégicos, enquanto nas escolas são apresentados conteúdos que poderão ser utilizados no cotidiano, ou não.

Essa dinâmica traz às aulas um aspecto desconectado da realidade, embora seja essencial aprender operações matemáticas, regras gramaticais, sistemas biológicos, dentre outros conhecimentos-base; no entanto, existe uma lacuna entre ensino e realidade que os professores buscam preencher. Mattar (2010, p. 10) acentua que "os alunos de hoje não são mais as pessoas para as quais nossos sistemas educacionais foram projetados, e em virtude disso a escola tem ensinado habilidades do passado".

A inovação pedagógica permeia a educação e relaciona-se com o processo criativo em sua concepção. Sobre a criatividade, os sujeitos de pesquisa reconhecem como uma nova percepção usar memes em aulas de Português. Ao serem questionados sobre as percepções em relação à oficina, os alunos A1, A3, A5 e A7 remeteram à diversidade de metodologias, que pode ser abordada em sala de aula: "Que existem várias formas de estudar não só olhando um professor escrevendo" (A3); "Como o meme deixa uma aula mais divertida" (A5); “Conhecimentos diversos através de dinâmicas utilizando memes” (A7).

Assim, revela-se que os alunos, com o emprego de inovações nas aulas de Português, percebem a necessidade da mudança das metodologias utilizadas. Segundo os dados, os alunos adaptam-se com facilidade ao novo e às inovações planejadas pelos docentes e aprendem com essas possibilidades.

Sobre a capacidade em aprender novas habilidades, Tapscott (2010) indica que

a capacidade de aprender novas coisas é mais importante do que nunca em um mundo no qual você precisa processar novas informações em grande velocidade. Os estudantes precisam ser capazes de pensar de forma 


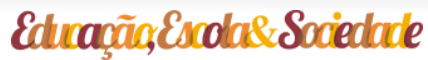

criativa, crítica e colaborativa para dominar os aspectos básicos e se destacar em leitura, matemática e ciências para ter competência de leitura e para reagir às oportunidades e desafios com rapidez, agilidade e inovação. Os estudantes precisam expandir sua base de conhecimento para além das portas de sua comunidade se quiserem se tornar cidadãos globais responsáveis e cooperativos em uma economia mundial cada vez mais complexa. (p. 156)

É emergente, na atual conjuntura, a expansão de práticas que possibilitem espaços de desenvolvimento de novas habilidades, nos quais os recursos digitais se destacam e, com eles, novos saberes e habilidades.

Embora os estudos dos memes relacionados à educação sejam pouco expressivos, no rol de produções científicas, há um movimento crescente em volta da atualização das práticas pedagógicas. À medida em que os processos comunicativos evoluem, o ensino de Português tende a passar por transformações, visto que um dos pilares da língua é a comunicação.

Destacamos os memes como processo comunicativo contemporâneo com forte influência do cenário tecnológico vigente. Esse recurso é, portanto, permeado de representações imagéticas; no entanto, existe certa resistência nessa transição do ensino de textos exclusivamente verbais para textos multimodais. Para Lendl (2018, p. 14), há uma disputa de espaço entre as representações verbais e as que favorecem tendências, uma vez que "é fácil notar nas escolas que há um privilégio quanto ao ensino do texto, em especial ao texto que é construído apenas com unidade verbal".

É vital romper paradigmas acerca de práticas que não são favoráveis ao desenvolvimento cognitivo do novo público que ocupa as escolas; entretanto, mostram-se certos obstáculos, nessa ruptura, como formação em detrimento dessas atualizações, criação de políticas públicas para efetivar um ensino contextualizado e satisfatório, dentre outros propulsores para uma educação de qualidade.

Nessa perspectiva, nosso estudo mostra-se pertinente, pois propõe relacionar o RMDM a práticas contemporâneas, porque tem em sua essência a multimodalidade, ao incorporar linguagens verbais, não verbais, recursos imagéticos e vivências, com enfoque maior na composição de sentido por meio da visualização, compreendida por Halliday (1985), em Gramática Sistêmico-Funcional (GSF) e, posteriormente, por Kress e Leeuwen (2000), nos estudos da funcionalidade das imagens na construção dos sentidos, em Gramática do Design Visual (GDV). Há esclarecimentos relativos às abrangências gramaticais a serem observados, como destaca Haddiday (1985): 


\section{EdurañäsEscolakSociedade}

A gramática vai além das regras formais de correção. É um meio de representar padrões de experiência [...]. Permite que os seres humanos construam uma imagem mental da realidade, para fazer sentido em suas experiências do que acontecem em torno deles e dentro deles. (p. 101).

Nesse aspecto, evidencia-se o contexto educacional do século XXI, que é permeado de demandas, desenvolvimento de habilidades, leituras multimodais, dentre outras competências que circundam a era digital. Por isso, ensinar exige a aceitação do novo (FREIRE, 2013), uma vez que acompanhar as evoluções sociais torna-se imprescindível na construção de espaços educacionais participativos e ligados às demandas do corrente século.

\section{Discussões e resultados}

O estudo foi realizado seguindo as etapas estabelecidas na metodologia, portanto, foram analisados dados por meio da realização de uma oficina, seguida da análise dos questionários, das entrevistas e de materiais produzidos.

Ao longo da oficina, intitulada "Português sem neura: descomplicando os descritores da Língua Portuguesa por meio dos memes", foram coletados os dados com os sujeitos de pesquisa. A oficina subdividiu-se em duas etapas, conforme consta no Quadro 1.

Quadro 1: Ações desenvolvidas

\begin{tabular}{|c|c|c|}
\hline Ações da Oficina & Abordagem do Professor & Ação dos Alunos \\
\hline $\begin{array}{l}\text { Ação 1: } \\
\text { Laboratório de } \\
\text { teoria e prática }\end{array}$ & $\begin{array}{l}\text { - Apresentação da Oficina } \\
\text { - Explicação do meme como um } \\
\text { recurso multimodal digital } \\
\text { - Importância das imagens na } \\
\text { construção e complementação de } \\
\text { sentidos } \\
\text { - Contexto e surgimento do meme e } \\
\text { apresentação dos componentes } \\
\text { multimodais pertencentes aos memes } \\
\text { - Utilização do meme como recurso } \\
\text { pedagógico } \\
\text { - Momento prático; produção de } \\
\text { memes }\end{array}$ & $\begin{array}{l}\text { - Interação sobre práticas e } \\
\text { metodologias ocorridas na } \\
\text { escola } \\
\text { - Produção de } 15 \text { RMDM, } \\
\text { memes } \\
\text { - Partilha das etapas de } \\
\text { produção dos memes }\end{array}$ \\
\hline $\begin{array}{l}\text { Ação 2: } \\
\text { Aprofundamento } \\
\text { dos conteúdos }\end{array}$ & $\begin{array}{l}\text { - Fundamentação acerca das } \\
\text { habilidades na área de Linguagens e } \\
\text { Códigos }\end{array}$ & $\begin{array}{l}\text { - Diálogo sobre o que é } \\
\text { aprendido na escola } \\
\text { - Breve relação com as }\end{array}$ \\
\hline
\end{tabular}




\begin{tabular}{|l|l|l|}
\hline & $\begin{array}{l}\text { Apresentação dos reguladores dessas } \\
\text { habilidades }\end{array}$ & avaliações externas, \\
- Detalhamento dos 23 descritores de & SPAECE, ENEM etc. \\
Língua Portuguesa & Momento de construção de \\
dez questões
\end{tabular}

Fonte: Dados da Pesquisa

Para dar início à oficina, fez-se um levantamento literário de fácil acesso e entendimento dos alunos, visto que, apesar do uso constante de memes, vez ou outra, mencionaram termos como inovação, multimodalidade, semiótica e os elementos que compõem os RMDM, segundo os estudos já realizados. No entanto, observou-se que, apesar do surgimento de termos não tão comuns, os alunos, no momento prático e no questionário on-line, apropriaram-se de tais conceitos.

Foram apontadas questões relativas à construção de sentido por meio das imagens, e percebido, esse processo como habitual, na organização social, até mesmo pelos participantes da oficina. Diante da corrente dinâmica social, há atribuições de sentido aos mais variados recursos comunicativos, "as necessidades sociais, culturais e políticas têm levado o homem a procurar novas formas e tecnologias de comunicação, bem como novas teorias de linguagem" (VIEIRA e SILVESTRE, 2015, p. 7).

Partindo para a parte prática da oficina, foi feito um desenho para orientar os eixos convergentes das produções e, com esses objetos, surgiram reflexões, com base na ótica do meme como um produto social, na maior parte das experiências adquiridas pelos leitores e, em nosso caso, os produtores dos RMDM. As temáticas recorrentes relacionaram-se a elaborações relativas à política, ao cotidiano, às drogas, relações afetivas, ao medo, mas, a de maior projeção, em todos os grupos (G1,G2 e G3), foi acerca das vivências em salas de aula e, na maior parte dos memes elaborados, relacionadas à obtenção de notas. Adiante, algumas produções dos alunos serão apresentadas. 


\section{Edurañãa,Escola\&Sociedace}

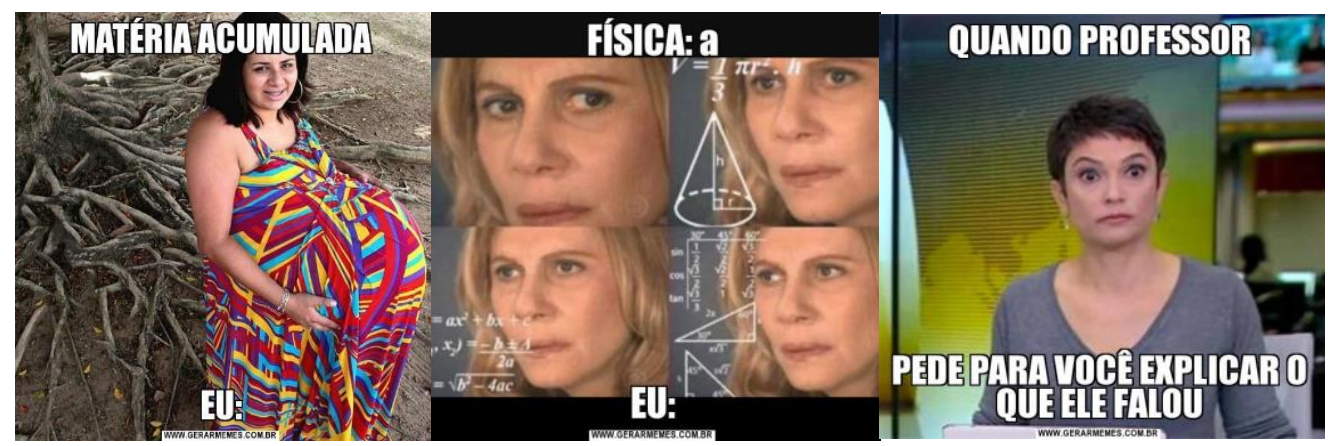

Figura 1: Memes elaborados pelos alunos no primeiro momento da oficina

Percebeu-se que os processos avaliativos incidem, frequentemente, nas produções dos alunos, talvez pelo fato de estarem imersos em espaços nos quais a avaliação se dá, prioritariamente, em função de diagnosticar o que o aluno "absorveu" em determinado mês e, a partir de então, atribuir-lhe uma porcentagem de aprendizado, assumindo esse processo como classificatório (LUCKESI, 1997). No RMDM apresentado pelo G2, o meme revela que, embora o aluno tenha estudado, a nota alcançada não satisfaz às suas expectativas, evidenciando, possivelmente, a existência de lacunas entre o que foi estudado, a maneira como foi estudado, as aulas dadas e o processo avaliativo. Outras produções apresentaram essa mesma vertente - o esforço dos alunos não condiz com a nota atingida, como ilustra a Figura 2.

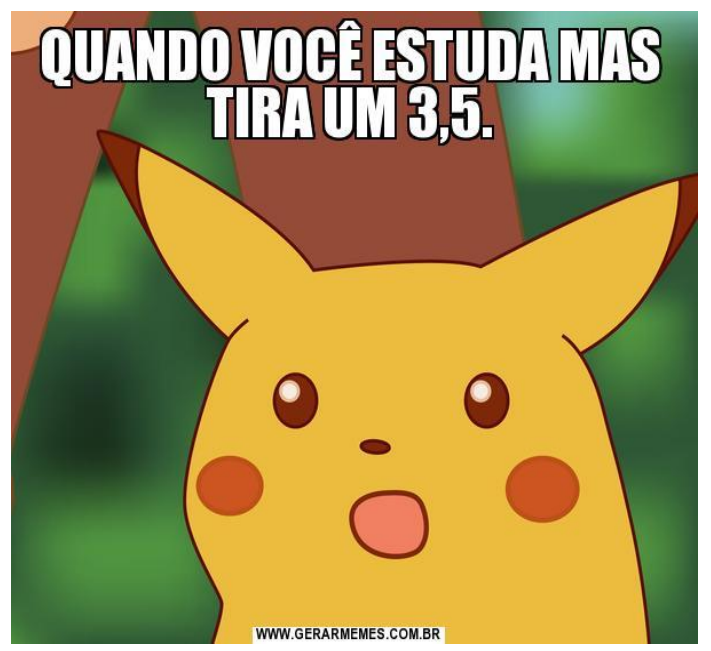

Figura 2: Meme elaborado pelos alunos do Grupo 2

A oficina proporcionou a produção de quinze RMDM que, posteriormente, embasaram a segunda etapa da oficina. Há, contudo, outros fatores relevantes presentes nos recursos produzidos para a discussão, em especial a relação de descredito em relação aos alunos, expressada no meme da Figura 3. 


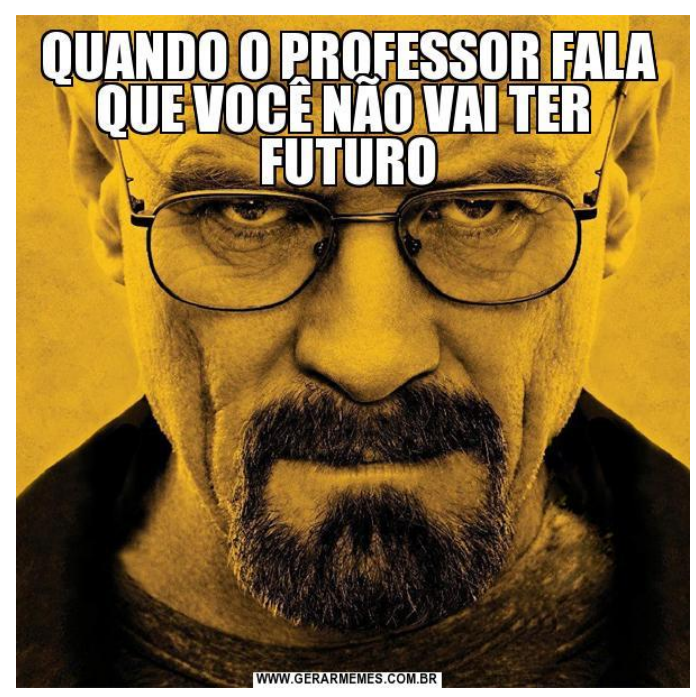

Figura 3: Meme elaborado pelos alunos do Grupo 3

Apresentado pelo G3, o meme, de certa forma, representa um estado, ou relações sociais. A produção mostra os resquícios de uma educação ordenada pela relação opressor e oprimido (FREIRE, 1987), embora deva ser considerado o teor humorístico de cada RMDM.

Sobre as análises da primeira etapa da oficina, percebeu-se que, ao longo das coletas, os grupos G1, G2 e G3 mantiveram-se motivados, envolvidos e atentos às informações e reflexões. Ao longo da abordagem da teoria, todos os alunos observavam silenciosamente e, quando questionados, respondiam rapidamente. Já durante a prática, mostraram divertimento, ao escolher e produzir os memes. As atitudes mostraram que as atividades envolvendo os memes motivam e envolvem os alunos.

Nas observações das interações dos grupos, registrou-se preocupação, por parte dos alunos, em construir enunciados, em especial, o grupo G1, composto pelos alunos A1 e A2, que estabeleceram uma parceria, pois, a todo momento, o aluno A1 consultava o A2 e viceversa.

No grupo G2, ocorreu uma reflexão sobre ortografia, discutida na forma de expressar a ideia do meme. Outro fator relevante, mostrado nas interações, refere-se aos conhecimentos prévios dos alunos evidenciados na oficina, desse modo o aluno A4 trouxe conceitos de memes usados em outro país, todavia, tinham sentido em seu contexto social, exemplificado aos demais participantes do grupo (A3 e A5) a tradução do meme (Inglês/Português). Na partilha das produções realizadas no grupo G3, pelos alunos A6 e A7, foi mantido o conflito na produção da atividade. Na observação, registrou-se o aluno A7 chamando a atenção para a pontuação e ortografia em todas as produções.

O grupo G3 apresentou um meme com erro ortográfico e embora o professor 


\section{Edurañãa,Escolar Sociedade}

estivesse atento à ortografia, a correção do erro foi abordada como forma de ajuda. Como resultado, a produção de atividades envolvendo memes oportunizam o entendimento do erro como parte integrante da aquisição da aprendizagem. Os conflitos que os erros trazem à sala de aula são, também, momentos de aprendizagem, uma vez que "o erro gera a necessidade de assimilar e acomodar conhecimentos para reaver o ponto de equilíbrio" (ASSIS et al., 2012, p. 53). Logo, é fundamental rever as formas de compreensão do erro, em uma perspectiva construtivista.

Feita essa breve discussão acerca das produções, conduzimos o segundo momento da oficina, que relaciona os memes com as habilidades a serem desenvolvidas na disciplina de Português. Apresentamos o conteúdo programado e mediamos o processo de construção dos enunciados, incentivando, nesses dois momentos, a autonomia dos alunos na criação dos memes, visto que "ensinar não é transferir conhecimento, mas criar as possibilidades para a produção ou a sua construção" (FREIRE, 2013, p. 25).

As ações de curtir, comentar e compartilhar tornaram-se comuns e recorrentes, no cotidiano dos usuários das redes sociais. O grupo G3, composto pelos alunos A6 e A7, em toda a etapa da produção, apresentava os resultados ao grupo G2. Sobre essa situação, Santaella (2014) menciona os hábitos de partilhar como forma de expressar e divulgar informações. Ao observar as situações na produção dos memes, registra-se a alegria e o orgulho em partilhar os resultados e a criatividade, ao longo da atividade. Ao serem questionados sobre a nova aprendizagem adquirida na vivência, dois alunos afirmaram ter mudado as percepções sobre as imagens: "O meme surge com o advento de experiências próprias do seu criador e da sociedade em que ele vive" (relato do aluno A4).

De fato, ao perceber a interdisciplinaridade que envolve as áreas do conhecimento e as possibilidades de construção, passa-se a ter "[...] aprendizagem investigativa, que trata os alunos não como receptores de informação, mas como produtores de conhecimento" (IDEO, 2010, p. 3). Isso mostra que o aluno, ao produzir os memes como prática pedagógica em sala de aula, reconhece que o processo se relaciona com os aspectos culturais de seu cotidiano.

A dinamicidade nos dois momentos da oficina ofertou aos alunos a possibilidade de construir e, ao mesmo tempo, interagir com os colegas, consultando-os sobre propostas de melhoria nos enunciados; erros de Português; como utilizar algumas ferramentas do editor de texto; e como adequar o meme escolhido à escrita dos enunciados. Notou-se um trabalho interdisciplinar em que foram levantadas algumas habilidades essenciais para $o$ 


\section{Edtuañangisolar Sociedace}

desenvolvimento humano, conceito basilar na teoria sociointeracionista de Vigotsky (1996).

Adiante, serão dispostas as considerações finais e a proposta de futuras investigações.

\section{Considerações}

Este estudo valida a relevância de se integrar novas ferramentas e habilidades às práticas educacionais, tendo em vista que os alunos reconhecem processos inovadores como impulsionadores da percepção dos conteúdos de Linguagens e Códigos. Incorporar temáticas atuais às práticas de ensino é, em suma, proporcionar espaços de aprendizagem mais colaborativos, emancipatórios e repletos de conhecimentos interdisciplinares.

Os alunos adaptaram-se e mostraram que se motivam com mais intensidade em aprender com as inovações propostas pelos professores; desse modo, ressalta-se a importância de se promover espaços dialógicos entre as diversas realidades e os variados contextos nas escolas, bem como conduzir momentos de participação ativa dos alunos, tendo em vista que nesta pesquisa foi possível desenvolver práticas colaborativas entre os pares; o diálogo, a criatividade, a utilização de recursos digitais, a oratória, a visão otimizada relativa aos conteúdos de Português; além do entendimento do erro como parte integrante da aquisição da aprendizagem.

Posteriormente, pretende-se aprofundar as análises dos dados coletados, de maneira a colaborar com o desenvolvimento das práticas educacionais em esferas mais abrangentes, fomentando contribuições ao fazer docente. Além disso, pretende-se ainda explorar o aperfeiçoamento de práticas que envolvam o RMDM, a fim de metodizar e torná-las acessíveis a outros docentes, do ponto de vista didático-pedagógico.

\section{Referências}

ASSIS, Lilian Bambirra de; PAULA, Ana Paula Paes de; BARETTO, Raquel de Oliveira; VIEGAS, Glauce. Estudos de caso no ensino da administração: o erro construtivo libertador como caminho para inserção da pedagogia crítica. Revista de Administração Mackenzie, São Paulo, v. 14, n. 5, São Paulo, set./out. 2013.

BAKHTIN, Mikhail. Estética da criação verbal. Tradução de Maria Emsantina Galvão Pereira. 2. ed. São Paulo: Martins Fontes, 1997.

DAWKINS, Richard. O gene egoísta. Tradução de Rejane Rubino. São Paulo: Companhia das Letras, 2007. 


\section{Edurañãa,Escola\&Sociedace}

ELLIOTT, John. Recolocando a pesquisa-ação em seu lugar original e próprio. In: GERALDI, Corinta Maria Grisolia, FIORENTINI, Dario; PEREIRA, Elisabete Monteiro de Aguiar. (Org.). Cartografias do trabalho docente: professor(a)-pesquisador(a). 2. ed. Campinas: Mercado das Letras, 2001, p. 137-152.

FREIRE, Paulo. Pedagogia do oprimido. 17. ed. Rio de Janeiro: Paz e Terra, 1987.

FREIRE, Paulo. Pedagogia da indignação: cartas pedagógicas e outros escritos. São Paulo: EdUNESP, 2000.

FREIRE, Paulo. Pedagogia da autonomia: saberes necessários à prática educativa. 44 ed. Rio de Janeiro: Paz e Terra, 2013.

HAGUETTE, Teresa Maria Frota. Metodologias qualitativas na Dociologia. 5. ed. Petrópolis: Vozes, 1997.

HALLIDAY, Michael. An introduction to functional grammar. London: Edward Arnold, 1985.

INSTITUTO EDUCADIGITAL. Design thinking para educadores. Nova York: IDEO, 2010.

JÓFILI, Zélia. Piaget, Vygotsky, Freire e a construção do conhecimento na escola. Educação:

Teorias e Práticas, Recife, v. 2, n. 2, p. 191-208, dez. 2002.

KRESS, Gunther; LEEUWEN, Theo van. Reading images: the grammar of visual design. London: Routledge, 2000.

LENDL, Aluizio; PINHEIRO, Michelle Soares. Multimodalidade: perspectivas teóricas e aplicadas. João Pessoa: Ideia, 2018.

LEWIN, Kurt. Problemas dinâmicos de grupo. Tradução de Miriam Moreira Leite. São Paulo: Cultrix, 1973.

LUCKESI, Cipriano Carlos. Avaliação da aprendizagem escolar: estudos e proposições. 6 ed. São Paulo: Cortez, 1997.

MARTINO, Luís Mauro Sá; GROHMANN, Rafael. A longa duração dos memes no ambiente digital: um estudo a partir de quatro geradores de imagens on-line. Fronteiras: estudos midiáticos, São Leopoldo, v. 19, n. 1, p. 94-101, jan./abr. 2017.

MATTAR, João. Games em Educação: como os nativos digitais aprendem. São Paulo: Pearson Prentice Hall, 2010.

MEILI, Angela Maria. Os memes no YouTube: uma aplicação da intertextualidade como categoria analítica. Comunicação \& Sociedade, São Bernardo do Campo, v. 35, n. 2, p. 353-381, jun. 2014.

VIEIRA, Josenia; SILVESTRE, Carminda. Introdução à Multimodalidade: contribuições da Gramática Sistêmico-Funcional, Análise de Discurso Crítica, Semiótica Social. Brasília: 2015

RODRIGUES, Alessandra; ALMEIDA, Maria Elizabeth Bianconcini de; VALENTE, José Armando. Currículo, narrativas digitais e formação de professores: experiências da pósgraduação à escola. Revista Portuguesa de Educaşão, Braga, v. 30, n. 1, p. 61-83, 2017. 


\section{EdurañänEscolarSaciedace}

SANTAELLA, Lucia. Gêneros discursivos híbridos na era da hipermídia. Bakbtiniana: Revista de Estudos do Discurso, São Paulo, v. 9, n. 2, p. 206-216, jul./dez. 2014

SILVA, Michel Pratini Bernardo da; FRANCELINO, Pedro Farias; MELO, Raniere Marques de. Relações dialógicas em memes da campanha publicitária "Eu sou a Universal". Prolíngua, João Pessoa, v. 12, n. 2, p. 175-187, jul./dez. 2017.

TAPSCOTT, Don. Geração digital: a crescente e irreversível ascensão da geração net. Tradução de Ruth Gabriela Bahr. São Paulo: Makron Books do Brasil, 1999.

VYGOTSKY, Lev Semionovitch. A formação social da mente. Tradução de José Cipolla Neto, Luis Silveira Menna Barreto, Solange Castro Afeche. Rio de Janeiro: Martins Fontes, 1996. 